\title{
Attenuation of CGAS/STING activity during mitosis
}

\author{
Brittany L Uhlorn ${ }^{1}$, Eduardo R Gamez², Shuaizhi Li ${ }^{3}$, Samuel K Campos ${ }^{1,3,4,5}$ (D)
}

\begin{abstract}
The innate immune system recognizes cytosolic DNA associated with microbial infections and cellular stress via the cGAS/STING pathway, leading to activation of phospho-IRF3 and downstream IFN-I and senescence responses. To prevent hyperactivation, cGAS/ STING is presumed to be nonresponsive to chromosomal self-DNA during open mitosis, although specific regulatory mechanisms are lacking. Given a role for the Golgi in STING activation, we investigated the state of the CGAS/STING pathway in interphase cells with artificially vesiculated Golgi and in cells arrested in mitosis. We find that whereas cGAS activity is impaired through interaction with mitotic chromosomes, Golgi integrity has little effect on the enzyme's production of cGAMP. In contrast, STING activation in response to either foreign DNA (cGAS-dependent) or exogenous cGAMP is impaired by a vesiculated Golgi. Overall, our data suggest a secondary means for cells to limit potentially harmful cGAS/ STING responses during open mitosis via natural Golgi vesiculation.
\end{abstract}

DOI 10.26508/Isa.201900636 | Received 26 December 2019 | Revised 8 July 2020 | Accepted 8 July 2020 | Published online 13 July 2020

\section{Introduction}

Cells possess intrinsic sensory pathways as part of the innate immune system to detect microbial infection or other physiological insults (1). Foreign nucleic acids are often recognized as pathogenassociated molecular patterns through a number of pattern recognition receptors (2), causing activation of NFKB-dependent inflammatory cytokine responses and/or IRF3/7-dependent type-I interferon (IFN-I) responses $(1,3)$. The cGAS/STING pathway is recognized as a central component of innate immunity for cytosolic DNA recognition and downstream IFN-I responses $(4,5,6,7,8)$. Cytosolic DNA is recognized by the enzyme cGAS, triggering production of the cyclic dinucleotide 2', $3^{\prime}$-cGAMP (9). STING, a transmembrane ER protein $(10,11)$, is activated by direct binding to CGAMP (12).

Upon activation by CGAMP at the ER, dimeric STING undergoes a conformational change (13) and traffics to the Golgi, a prerequisite for assembly of the STING/TBK1/IRF3 complex and downstream IFN-I responses (14). cGAMP-dependent STING recruitment of TBK1 (15) can lead to phosphorylation of IRF3 and NFKB, stimulating both IFN-I and proinflammatory cytokine responses $(10,16,17)$. Trafficking of STING to the Golgi is regulated by several host factors, including iRHOM2-recruited TRAP $\beta$ (18), TMED2 (19), STIM1 (20), TMEM203 (21), and ATG9A (22). STING activation at the Golgi requires palmitoylation (23) and ubiquitylation $(24,25)$, allowing for assembly of oligomeric STING and recruitment of TBK1 and IRF3 $(26,27,28)$. STING also interacts with the ER adaptor SCAP at the Golgi to facilitate recruitment of IRF3 (29). In addition to innate defense against microbial infections, CGAS/STING is involved in cellular responses to DNA damage and replicative/mitotic stress (5, 30, 31, 32, 33, 34, 35, 36). DNA damage, replicative stress, chromosomal instability, and mitotic errors can lead to the formation of micronuclei which can trigger antiproliferative IFN-I and senescence responses via CGAS/STING (37).

Unabated activation of cGAS/STING can lead to harmful autoinflammatory and senescence responses, exemplified by type-I interferonopathies associated with mutations in STING $(38,39,40,41)$ or mutations in the DNases TREX1 and DNASE2 that normally clear cells of cGAS-stimulatory DNA $(42,43,44,45)$. Given the harmful effects of cGAS/ STING hyperactivation, cells need regulatory mechanisms to avoid selfstimulation of cGAS/STING during mitosis. Cytosolic compartmentalization of cGAS was initially proposed as a mechanism, but nuclear chromosomes and cytosolic compartments mix upon mitotic nuclear envelope breakdown (NEBD), suggesting a more elaborate means of cGAS/STING attenuation during cell division.

The chromatinized nature of cellular genomic DNA has been proposed to mitigate cGAS/STING activity, with histones structurally marking DNA as "self." This is an attractive model as many DNA viruses sensed by cGAS/STING upon initial entry, trafficking, and uncoating (before viral DNA replication) contain either naked, unchromatinized dsDNA (e.g., herpesviridae $(46,47))$ or DNA that is packaged with non-histone viral core proteins (e.g., adenoviridae, poxviridae, and asfarviridae $(48,49,50,51,52)$ ).

Because cGAS localizes to condensed chromosomes upon NEBD $(35,53)$, others have asked whether cGAS is activated by chromosomes, and if not, what mechanisms exist to prevent such selfactivation. Recent studies have revealed that i) chromosome-bound cGAS is tightly tethered to chromatin, potentially via interactions with $\mathrm{H} 2 \mathrm{a} / \mathrm{H} 2 \mathrm{~b}$ dimers, ii) chromatin interaction does not involve the DNA-binding domains of cGAS required for "typical" activation by dsDNA, and iii) that chromosome binding results only in weak activation of CGAS with relatively low production of $\operatorname{cGAMP}(34,53$, 54).

\footnotetext{
${ }^{1}$ Cancer Biology Graduate Interdisciplinary Program, The University of Arizona, Tucson, AZ, USA ${ }^{2}$ Department of Physiology, The University of Arizona, Tucson, AZ, USA ${ }^{3}$ Department of Immunobiology, The University of Arizona, Tucson, AZ, USA ${ }^{4}$ BIO5 Institute, The University of Arizona, Tucson, AZ, USA ${ }^{5}$ Department of Molecular and Cellular Biology, The University of Arizona, Tucson, AZ, USA
}

Correspondence: skcampos@email.arizona.edu 
Given the importance of the Golgi in STING-dependent activation of IRF3, we hypothesize a parallel mechanism for cGAS/STING regulation during open mitosis-Golgi vesiculation $(55,56)$. Here, we find that chemical dispersal of the Golgi abrogates cGAS/STING-dependent phospho-IRF3 responses to transfected DNA. Furthermore, we show that cGAS/STING activity in response to transfected DNA is diminished during open mitosis, correlating with the vesiculated state of the mitotic Golgi. This Golgi-dependent weakening of cGAS/ STING responses to transfected DNA occurs at the level of STING, as cGAS activity is down-regulated upon mitotic chromosome binding but largely unaffected by Golgi integrity. The vesiculated state of the mitotic Golgi may, therefore, provide an additional safeguard mechanism, ensuring that potentially harmful cGAS/STING responses to self-DNA are minimized during cell division.

\section{Results and Discussion}

\section{Human keratinocytes respond to foreign DNA via cGAS/STING}

We chose to investigate activity of the cGAS/STING pathway in HaCaTs, a spontaneously immortalized human keratinocyte cell line (57). This cell line is a good model for primary keratinocytes that serve a barrier function and as host cells for a number of viral infections, including papillomaviruses, herpesviruses, mosquitotransmitted alphaviruses and flaviviruses $(58,59,60,61,62,63$, 64), and numerous bacterial and fungal pathogens $(65,66)$. Although prior work has shown that $\mathrm{HaCaT}$ cells express an intact cGAS/STING pathway $(60,67,68,69,70,71)$, we sought to ensure the cGAS/STING pathway was functional and responsive in our HaCaT line and that this pathway was the primary mode of IRF3 phosphorylation in response to foreign DNA.

HaCaTs were transfected with siRNAs targeting the cGAS/STING pathway and subsequently transfected with endotoxin-free dsDNA plasmid pGL3 (Fig 1). IRF3 was phosphorylated (pIRF3) in response to DNA transfection, exemplifying the ability of exogenous dsDNA to activate the CGAS/STING pathway in HaCaTs. IRF3 phosphorylation was impaired when pGL3 was transfected after siRNA knockdown of

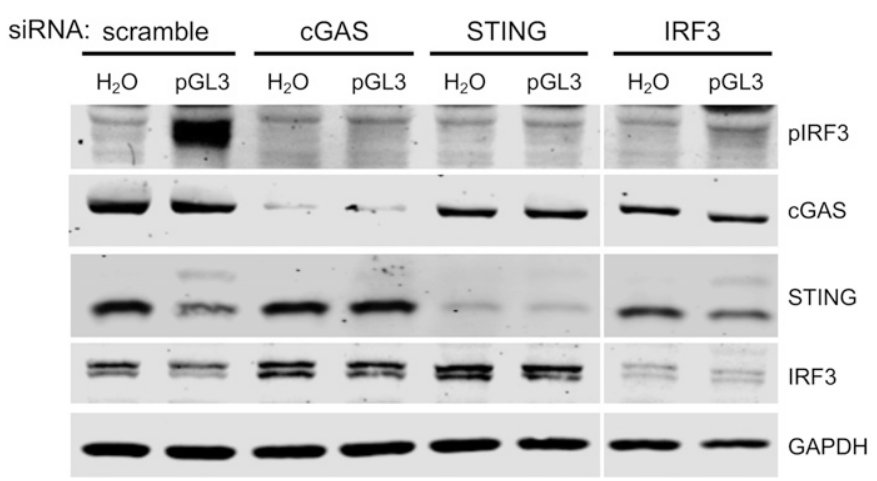

Figure 1. Human keratinocytes respond to foreign DNA via CGAS/STING. $\mathrm{HaCaTs}$ were transfected with siRNAs for $16 \mathrm{~h}$, followed by transfection with 500 ng pGL3 or water for 90 min. Lysates were analyzed for cGAS/STING component knockdown and pathway activity by SDS-PAGE and Western blot Source data are available for this figure.
CGAS, STING, or IRF3, confirming that HaCaT cells use the cGAS/ STING pathway as the primary mechanism of activating a pIRF3 response to foreign DNA.

\section{Golgi vesiculation but not fragmentation impairs cGAS/STING activity at the level of STING}

Activated STING traffics to the Golgi to oligomerize and complex with TBK1/IRF3. Because Golgi trafficking is critical for STING/TBK1/ IRF3 complex assembly and activation, we hypothesized that a vesiculated Golgi would prevent CGAS/STING from responding to foreign DNA. To test this idea, we used the Golgi-disrupting compounds nocodazole (NOC), golgicide A (GCA), and brefeldin A (BFA). At high dose, NOC treatment causes reversible Golgi fragmentation and redistribution to ER-exit sites (ERES) (72), whereas GCA and BFA treatment cause more drastic Golgi vesiculation and dispersal by targeting the Arf1 guanine nucleotide exchange factor $\operatorname{GBF} 1(73,74)$. Indeed, NOC treatment of HaCaT cells caused a pronounced fragmentation of the Golgi as seen by immunofluorescence (IF) microscopy for trans-Golgi markers p230 and TGN46, whereas GCA and BFA treatment completely vesiculated the Golgi apparatus (Fig $2 \mathrm{~A}$ and $\mathrm{B}$ ), mimicking the dispersed mitotic Golgi. As expected, transfection of $\mathrm{pGL3}$ resulted in clustering of STING with p230- and TGN46-positive Golgi membranes and nuclear import of IRF3, indicative of pathway activation (Fig 2A-D). Addition of GCA or BFA completely abrogated activation of STING and IRF3, whereas NOC had minimal effect, suggesting that whereas a fragmented Golgi can support pGL3-stimulated STING/IRF3 activation, a dispersed Golgi cannot (Fig 2A-D). Likewise, IRF3 phosphorylation was induced upon transfection of HSV-60 oligonucleotide DNA, calf-thymus DNA (CTD), or pGL3 plasmid in HaCaTs with intact or fragmented Golgi; however, GCA- or BFA-mediated Golgi vesiculation impaired DNAdependent IRF3 phosphorylation (Fig 3A), in agreement with prior literature (75).

To determine if the requirement for intact Golgi was specific for CGAS/STING or involved a more broad inhibition of IRF3 phosphorylation, we investigated activation of the RIG-I-like receptors (RLRS). The dsRNA-mimic polyinosinic-polycytidylic acid (pIC) stimulates RLR-family members which recognize intracellular viral RNA products through the mitochondria-resident adaptor protein MAVS to elicit NFKB inflammatory and IRF3/7-dependent IFN-I responses (76, 77). pGL3-dependent PSTING, PTBK1, and pIRF3 responses were abolished by Golgi dispersal (Fig 3B and C). In contrast, transfection of pIC elicited PTBK1 and pIRF3 responses regardless of GCA treatment (Fig 3B and D), suggesting that the CGAS/STING pathway, but not the RLR pathway, is regulated by Golgi morphology. Exogenous stimulation of HaCaT cells with the STING ligand CGAMP was sensitive to GCA-mediated Golgi disruption (Fig 3E), and GCA had no effect on CGAMP production in response to pGL3 transfection (Fig $3 F$ ), indicating that Golgi dispersal blocked the pathway downstream of cGAS.

The GCA-induced repression of CGAS/STING activation was also reflected when measuring $\mathrm{pGL3}$-dependent downstream transcriptional responses. RT-qPCR at 4 and $8 \mathrm{~h}$ post-pGL3 transfection revealed that induction of IFNB1 (Fig 4A), the ISGs Viperin, IFI6, HERC5, IFIT2, and IFIT3 (Fig 4B-F), and chemokines CXCL10 and CXCL11 (Fig 4G and $\mathrm{H}$ ) was significantly dampened in the presence of 
A
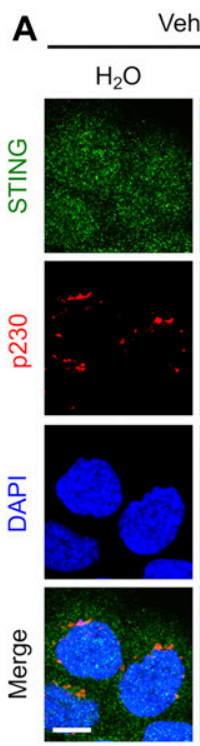

ehicle

NOC
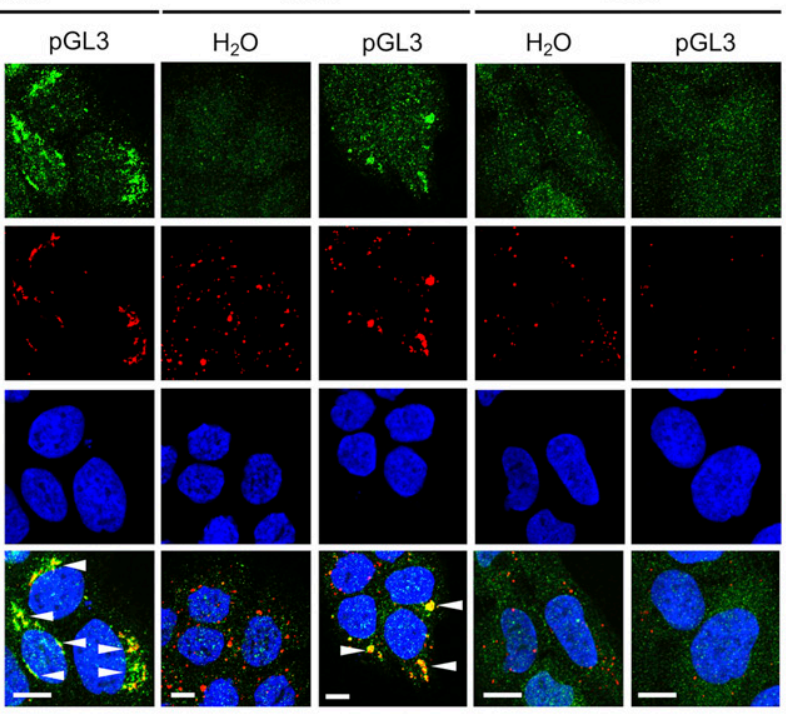

B
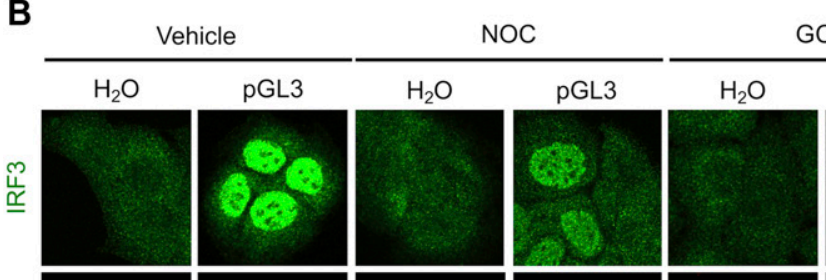

\begin{abstract}
GCA
\end{abstract}
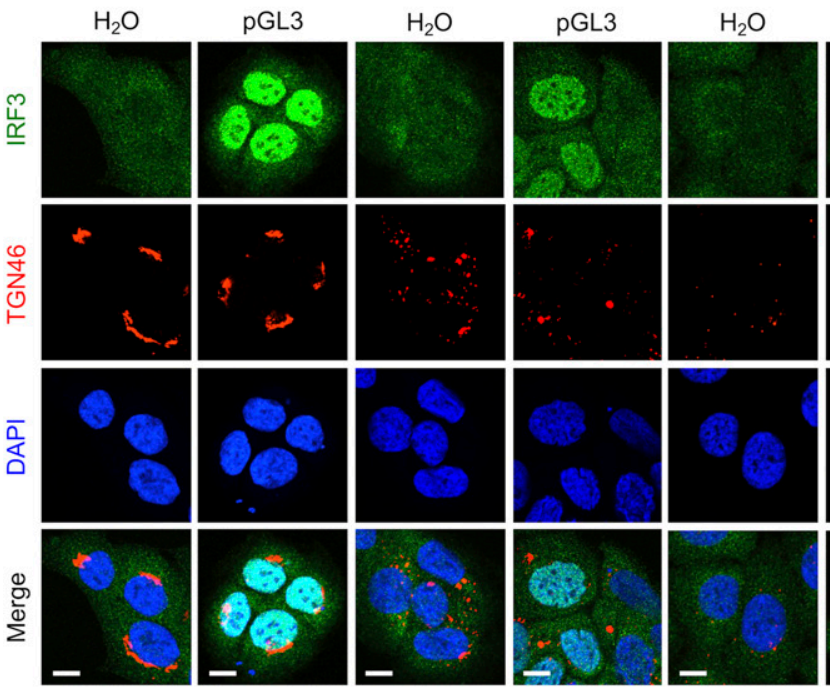

Figure 2. Effects of Golgi disruption on DNA-dependent subcellular localization of STING and IRF3.

$\mathrm{HaCaT}$ cells were pretreated with vehicle, NOC, GCA, or BFA before a 90-min transfection with $\mathrm{H}_{2} \mathrm{O}$ or pGL3. (A, B) Cells were fixed and stained for (A) STING and p230 or (B) IRF3 and TGN46 before DAPI staining. (A, B) Representative micrographs are shown in (A, B), white arrowheads indicate overlap. (C, D) Manders' overlap coefficients from multiple micrographs were plotted for (C) STING:p230 and (D) IRF3:DAPI. ${ }^{\star} P<0.01,{ }^{\star * \star} P<0.0001$. Scale bars $=10 \mu \mathrm{m}$.

GCA. Overall, these data show that cGAS/STING activity is blunted at the level of STING upon Golgi vesiculation, similar to what may occur during mitosis.

\section{cGAS/STING activity is attenuated during mitosis}

We next investigated the impact of natural mitotic Golgi vesiculation on the ability of cGAS/STING to sense and respond to exogenous DNA. Secretory ER to Golgi traffic is blocked during mitosis $(78,79,80,81)$. Golgi integrity is dependent on cargo transport from ERES, and mitotic arrest of COPII-dependent ERES traffic causes Golgi dispersal $(82,83)$. As assembly of the activated STING/TBK1/
IRF3 complex requires STING transport from ERES to the Golgi (14), we hypothesized that mitotic Golgi dispersal and inactivation of ERES would blunt cGAS/STING responses.

We devised a method to synchronize cells at prometaphase (Fig $5 A)$. Briefly, cells were cultured at $100 \%$ confluence for $48 \mathrm{~h}$ in $1 \%$ serum, leading to quiescent arrest in $\mathrm{G}_{0}$. Cells were released by replating in $10 \%$ serum, allowing for $G_{1}$ reentry and progression to $\mathrm{S}$ phase. At $24 \mathrm{~h}$ post $-\mathrm{G}_{0}$ release, cells were synchronized at prometaphase with low-dose NOC for 12 h. Upon NOC washout, synchronized cells progressed through mitosis, returning to $G_{1}$ within $3 \mathrm{~h}$. Propidium iodide (PI) staining showed cells enriched at $\mathrm{G}_{2} / \mathrm{M}$ after NOC treatment, and the most cells back in $\mathrm{G}_{1}$ by $3 \mathrm{~h}$ post-NOC 
A
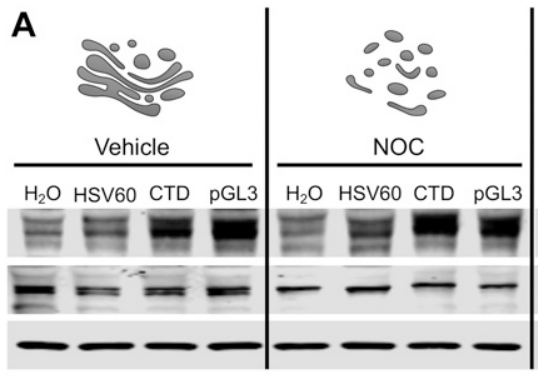

B

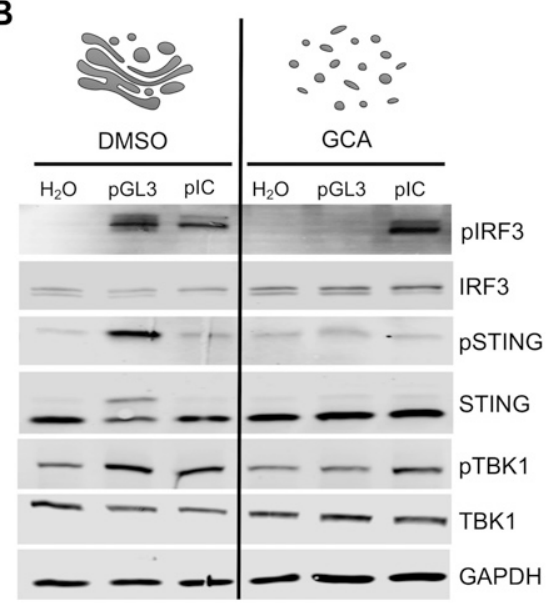

C

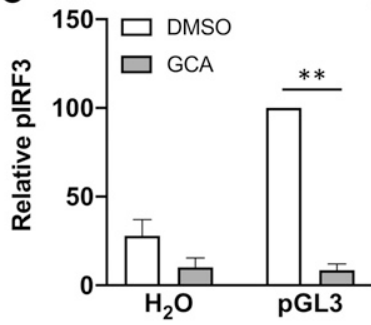

D

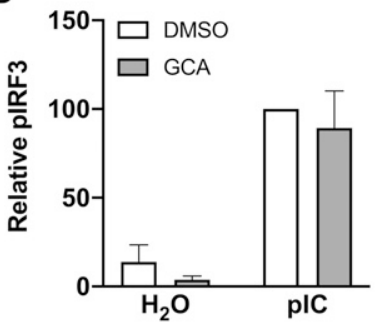

E

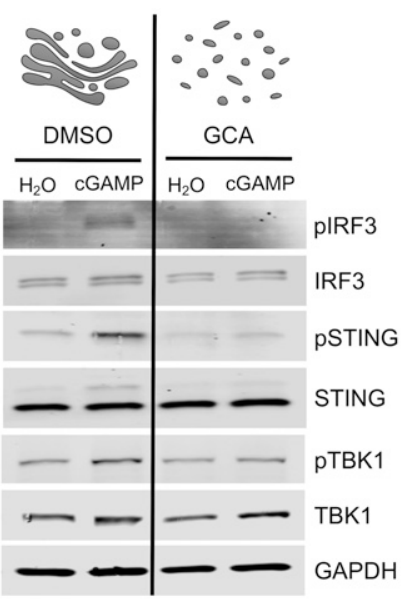

$\mathbf{F}$

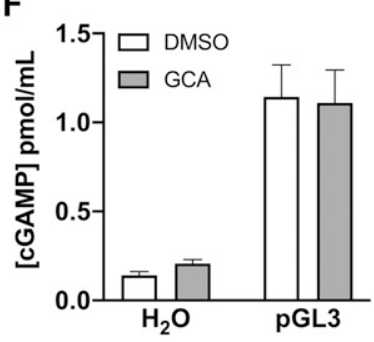

Figure 3. Effects of Golgi disruption on cGAS/STING activity.

(A) Cells were treated with vehicle, nocodazole (NOC), golgicide $A$ (GCA), or brefeldin $A$ (BFA) for $1 \mathrm{~h}$ prior and during a 90-min transfection with HSV-60 oligonucleotide, calf-thymus DNA (CTD), or plasmid pGL3. (B, C, D) Transfection of vehicle- or GCA-treated cells with $\mathrm{pGL} 3$ or pIC, and (C, D) densitometric quantification of pIRF3 blots. ${ }^{* *} P<0.001, \mathrm{n}=5$ biological replicates. (E) Vehicle- or GCA-treated cells were treated with $\mathrm{H}_{2} \mathrm{O}$ or $12.5 \mu \mathrm{g}$ CGAMP for $90 \mathrm{~min}$ before SDS-PAGE and Western blot for CGAS/STING pathway components. (F) CGAMP production in vehicleand GCA-treated cells upon pGL3 transfection. $\mathrm{n}=3$ biological replicates, with $\mathrm{n}=2$ technical replicates each.

Source data are available for this figure. release (Fig 5A). Phosphorylated histone $\mathrm{H} 3$ ( $\mathrm{pH} 3$ ) was enriched in NOC-synchronized cells, decreasing as cells returned to $\mathrm{G}_{1}$ (Fig 5B).

We used this scheme to assess mitotic cGAS/STING responses to pGL3 transfection. Cells were transfected while in the prometaphase after the $12 \mathrm{~h}$ NOC sync (non-released group, NR), or at 0 , 60,120 , or 180 min post-release, and cGAS/STING activity was assessed 90 min post-transfection. Cells arrested at the prometaphase mounted a very weak pIRF3 response to pGL3 transfection compared with cells which had returned to $\mathrm{G}_{1}$ after $\mathrm{a} 3 \mathrm{~h}$ release (Fig 5B, compare lanes 6-10). These arrested cells had condensed chromosomes with dispersed Golgi (Fig 5D, NR). STING had a cytosolic but granular distribution in arrested cells, which did not change upon pGL3 transfection. In contrast, STING clearly localized to p230-positive Golgi structures upon pGL3 transfection of $\mathrm{G}_{1}$ cells (Fig 5D and E). On average, across four independent synchronization experiments, pGL3-dependent phosphorylation of IRF3 was attenuated during mitosis, only becoming robust at $180 \mathrm{~min}$ (Fig 5C), when the bulk population of cells reached $\mathrm{G}_{1}$ and had intact Golgi with clear STING localization upon pGL3 transfection (Fig 5D and E).

\section{cGAS and STING are nonresponsive during mitosis}

Recent work has shown that upon NEBD, cGAS localizes to mitotic chromosomes via direct binding to $\mathrm{H} 2 \mathrm{a} / \mathrm{H} 2 \mathrm{~b}$ dimers (53). However, this binding is not via the DNA-binding domains of cGAS that underlie DNA-dependent activation, resulting in a relatively low production of cGAMP. Thus, chromatin appears to blunt cGAS activation $(34,53)$, suggesting a means for the cell to avoid cGASdriven IFN responses to self-chromosomes during open mitosis. One unexplored aspect is whether chromatin-bound cGAS, or the pool of cGAS that might remain cytosolic during open mitosis, would still be responsive to foreign (naked) DNA-and whether that activation would then cause IRF3 phosphorylation.

We observed only low activation of IRF3 in response to pGL3 transfection in NOC-arrested prometaphase cells (Figs 5B and C and 6A). To determine if the dampening of the pathway in these arrested cells was at the level of CGAS or STING, we measured cGAMP production in response to pGL3 transfection and examined cGAS subcellular distribution. Similar to pIRF3, cGAMP production was 

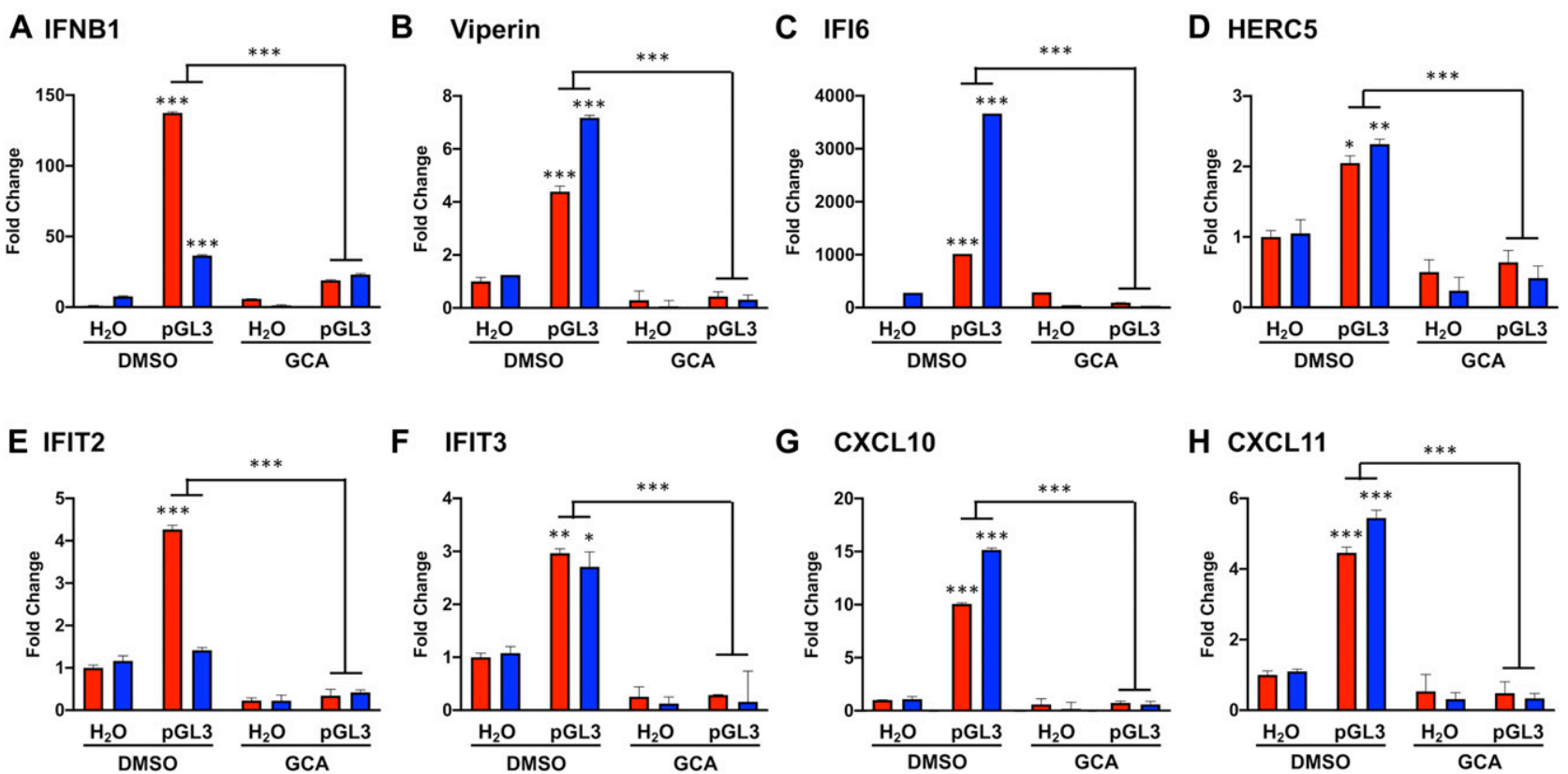

Figure 4. Golgi vesiculation impairs DNA-dependent IFN, ISG, and chemokine gene transcription.

HaCaT cells were treated with GCA or vehicle for $1 \mathrm{~h}$ before a 90-min pGL3 transfection. (A, B, C, D, E, F, G, H) Transcript levels of (A) IFNB1, (B, C, D, E, F) ISGs, and (G, H) chemokine genes were measured via RT-qPCR and normalized to TATA-binding protein. ${ }^{*} P<0.01$, ${ }^{* *} P<0.001$, ${ }^{\star * *} P<0.0001$, for comparisons of 4 and 8 h DMSO-treated pGL3 groups to 4 and $8 \mathrm{~h}$ DMSO-treated $\mathrm{H}_{2} \mathrm{O}$ controls and for 4 and $8 \mathrm{~h}$ DMSO-treated pGL3 groups to 4 and $8 \mathrm{~h}$ GCA-treated pGL3 groups, $\mathrm{n}=3$ technical replicates.

blunted in transfected arrested cells (NR) compared with asynchronous interphase cells (Fig 6B). Confocal microscopy of asynchronous cells revealed that cGAS was mostly nuclear, although some signal was evident within the cytosol (Fig 6C), in agreement with a recent report (54). Within arrested cells, the vast majority of cGAS was chromatin bound and Golgi were well dispersed (Fig 6D). These results agree with recent work showing that cGAS is predominantly nuclear, regardless of cell cycle phase or activation status (54). Combined, our data suggest that chromatin-bound cGAS is unable to produce a robust cGAMP response to either chromosomes or transfected DNA.

Although we detected slightly elevated levels of cGAMP in unstimulated arrested versus asynchronous cells (Fig 6B), the subtle difference was not significant, consistent with recent work showing cGAS generates only low levels of cGAMP upon activation by chromatin $(34,53)$. Mitotic cells could potentially take up exogenous CGAMP via SLC19A1 $(84,85)$ or LRRC8 $(86)$ transporters, or directly from neighboring cells $(87,88)$. Recent work has revealed a primordial role for CGAMP-dependent STING activation in triggering autophagy through WIPI2/ATG5 in a TBK1/IRF3-independent manner (75). These Golgiderived autophagosomes promote clearance of cytosolic DNA and incoming DNA viruses such as HSV1 (75). Although mitotic cells appear to avoid classical induction of autophagy via CDK1 phosphorylation of ATG13, ULK1, and ATG14 $(89,90)$, downstream STINGdependent activation of autophagophore formation/elongation via WIPI2/ATG5 during open mitosis could be deleterious to daughter cell survival $(91,92)$.

Considering the potential for activation of STING by low levels of endogenous CGAMP or uptake of exogenous cGAMP, we assessed whether mitotic Golgi vesiculation would prevent STING activation by exogenous CGAMP. Neither transfection of pGL3 nor addition of exogenous CGAMP stimulated pIRF3 or PSTING in arrested cells (Fig $6 \mathrm{E}$ ), suggesting that Golgi vesiculation reinforces CGAS inactivation as a secondary barrier to CGAS/STING activation during open mitosis. During revision of this manuscript, an article was published describing how CGAS is phosphorylated and inactivated by the kinase Cdk1-cyclin B during mitosis (93). Using different cell types, their findings largely agree with what we observe herein-that chromosome-bound CGAS is inactive to stimulation by exogenous transfected DNA in mitosis and that STING is nonresponsive to exogenous cGAMP in mitotic cells. Interestingly, when mitotic cGAS inactivation was blunted by the use of the Cdk1 inhibitor RO-3306, despite increased cGAMP levels or addition of exogenous CGAMP, there was still lack of activated PSTING and pIRF3 (93), consistent with our data suggesting pathway inhibition by a vesiculated Golgi. Fragmentation and vesiculation of the Golgi is a natural $G_{2} / M$ checkpoint for mitotic progression $(55,94,95,96)$, thus we are unable to experimentally prevent Golgi dispersal during mitosis to determine if cGAMP-dependent STING activity would then be restored.

Given that CGAS/STING-dependent elevation of pIRF3 during mitosis (particularly during prolonged mitosis) can induce apoptosis (53) and activated STING can induce a potentially harmful autophagic response (75), a parallel dampening mechanism like Golgi dispersal likely serves an important role to limit potentially harmful cGAS/STING signaling during open mitosis. Furthermore, many other viruses and bacteria induce dramatic alteration of Golgi membranes during infection $(97,98,99,100,101)$. Microbial alteration of Golgi integrity may be an important unrecognized tactic to blunt host cGAS/STING responses. 
A
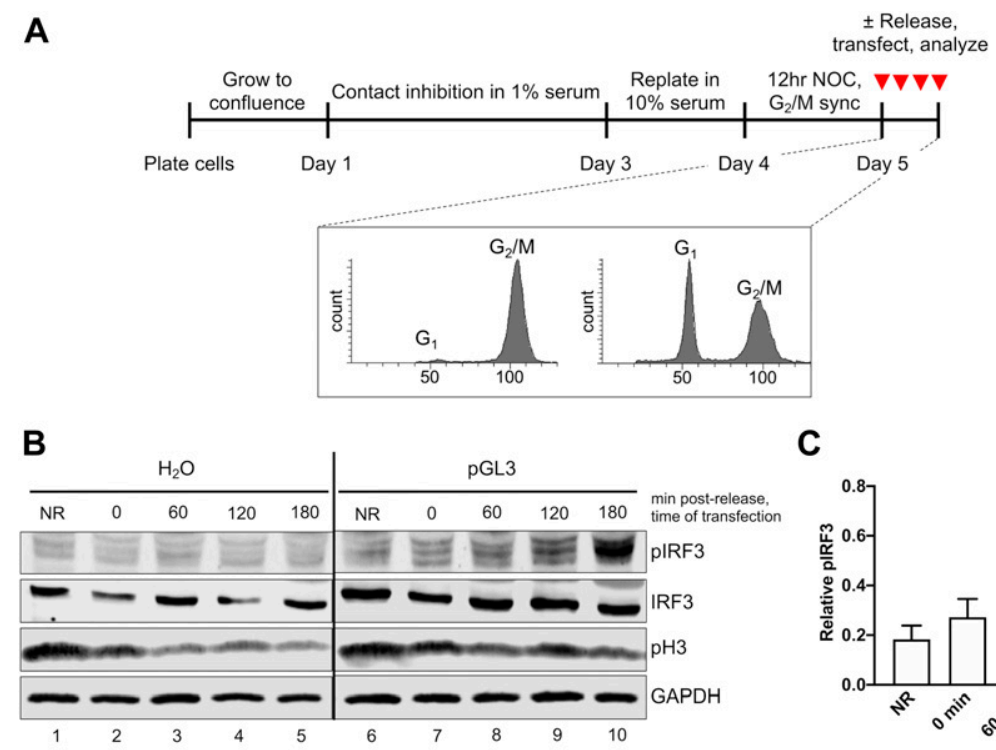

D

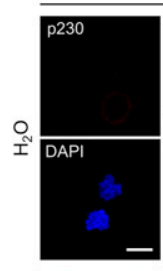

NR

C
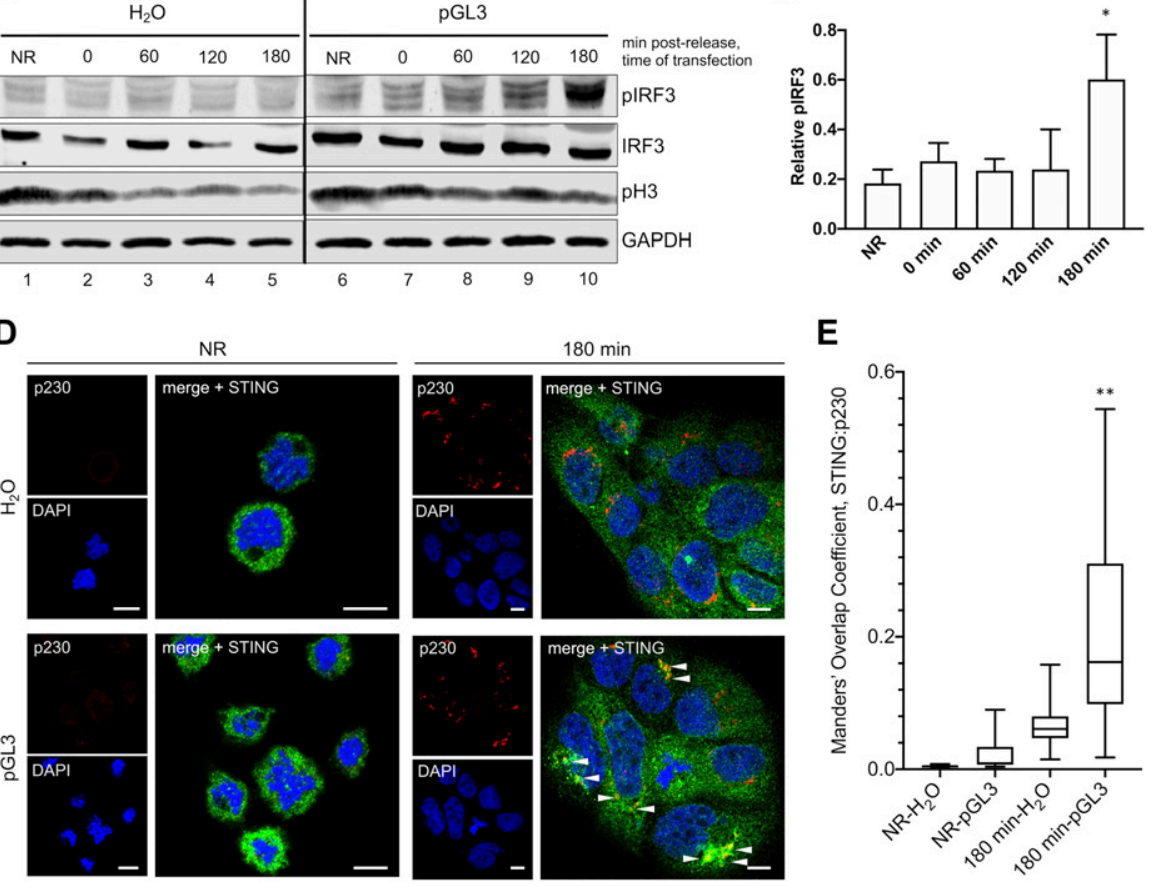

$180 \mathrm{~min}$

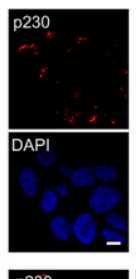

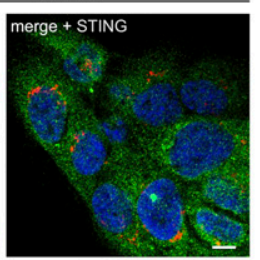

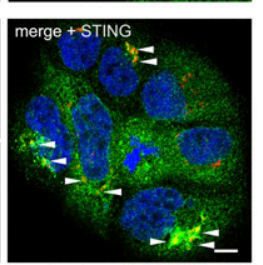

E

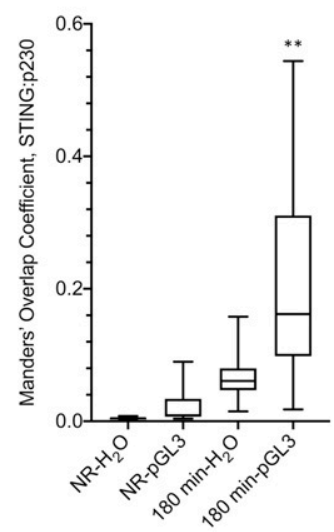

Figure 5. CGAS/STING activity is attenuated during mitosis.

(A) Cell synchronization method. Cells were presynchronized in $\mathrm{G}_{1}$ by contact inhibition and growth in low serum. Cells were then released by replating at subconfluence in $10 \%$ serum and synchronized in prometaphase with NOC. Cell cycle analysis by propidium iodide staining. Cells were transfected with $\mathrm{pGL} 3$ for $90 \mathrm{~min}$ at various times post-release from NOC. (B) pIRF3 activation in response to pGL3 was dampened when arrested cells were transfected, gradually returning as cells completed mitosis and returned to interphase. (C) Densitometric quantification of relative pIRF3 increase in response to pGL3 transfection across multiple blots. ${ }^{*} P<0.05$, for comparison of 180 min to NR groups, $n=4$ independent biological replicates. (D) Golgi localization of STING was impaired when arrested cells (NR) were transfected, but was restored upon return to interphase (180 min). (E) Manders' overlap coefficients from multiple micrographs were plotted for STING:p230, ${ }^{* *} P<0.001$, scale bars $=10 \mu \mathrm{m}$.

\section{Materials and Methods}

\section{Tissue culture}

HaCaT cells were grown in high-glucose DMEM (11965-092; Gibco) supplemented with 10\% FBS (A31606-02; Gibco) and antibioticantimycotic (15240062; Thermo Fisher Scientific). Cells were cultured at $37^{\circ} \mathrm{C}$ with $5 \% \mathrm{CO}_{2}$ and passaged every $2-3 \mathrm{~d}$ to maintain subconfluence.

\section{Nucleic acid transfections}

HaCaTs were plated at 60,000 cells per well in a 24-well plate. Cells were transfected with 500 ng dsDNA oligonucleotide HSV-60 (tlrlhsv-60n, 60 bp; InvivoGen), calf-thymus DNA (D4764, >20 kb; SigmaAldrich), or endotoxin-free pGL3 (E1751, 5.3 kb; Promega), or $500 \mathrm{ng}$ high molecular weight poly(l:C) (tlrl-pic, 1.5-8 kb; InvivoGen) using Lipofectamine 2000 (11668; Thermo Fisher Scientific) in OptiMEM (Life Technologies). At various time points post-transfection, cells were washed once with PBS and lysed in 1× RIPA lysis buffer $(50 \mathrm{mM}$
Tris- $\mathrm{HCl}, \mathrm{pH} 8.0,150 \mathrm{mM} \mathrm{NaCl}, 1 \% \mathrm{NP} 40,0.5 \%$ sodium deoxycholate, and $0.1 \%$ SDS), supplemented with $1 \times$ reducing SDS-PAGE loading buffer (62.5 mM Tris, pH 6.8, 10\% glycerol, 2\% SDS, 0.5\% bromophenol blue, and $5 \% \beta$-mercaptoethanol), $1 \times$ protease inhibitor cocktail (P1860; Sigma-Aldrich), $1 \mathrm{mM} \mathrm{PMSF,} \mathrm{and} \mathrm{1 \times} \mathrm{PhosSTOP}$ phosphatase inhibitor cocktail (04906845001; Roche). Samples were boiled for $5 \mathrm{~min}$ at $95^{\circ} \mathrm{C}$ and stored at $-80^{\circ} \mathrm{C}$ until separated and analyzed by SDS-PAGE.

\section{siRNA experiments}

Pooled scramble (sc-37007), cGAS (sc-95512), STING (sc-92042), and IRF3 (sc-35710) siRNA duplexes were obtained from Santa Cruz Biotechnologies. HaCaTs were plated at 30,000 cells per well in a 24well plate with Ab/Am-free DMEM/10\% FBS. The following day, cells were washed twice with PBS and the PBS replaced with OptiMEM. Cells were transfected with 50 nM siRNA using Lipofectamine RNAiMax (13778150; Life Technologies). At $16 \mathrm{~h}$ post-siRNA transfection, cells were washed twice with PBS and the PBS was replaced with $\mathrm{Ab} / \mathrm{Am}$-free DMEM/10\% FBS. Cells were transfected with $\mathrm{pGL3}$ 
A

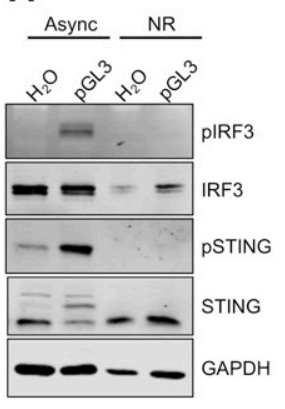

D
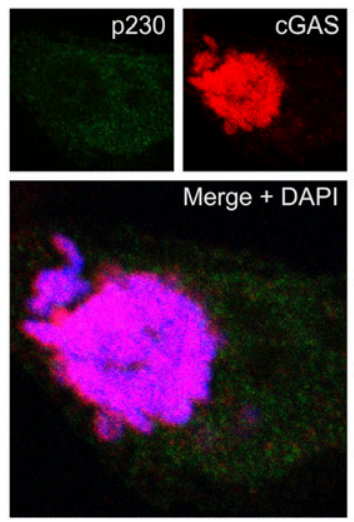

B

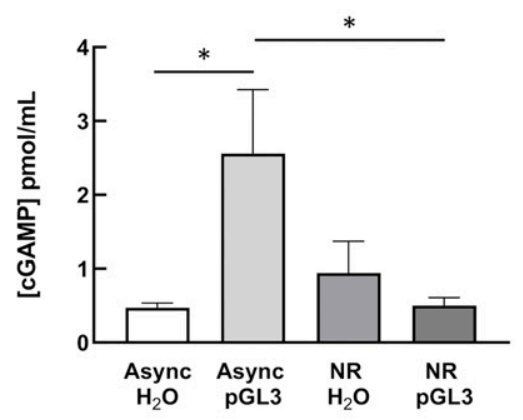

C

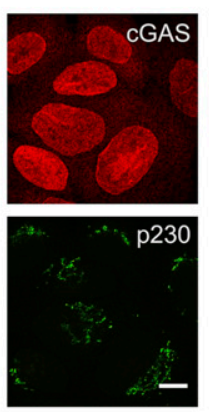

E

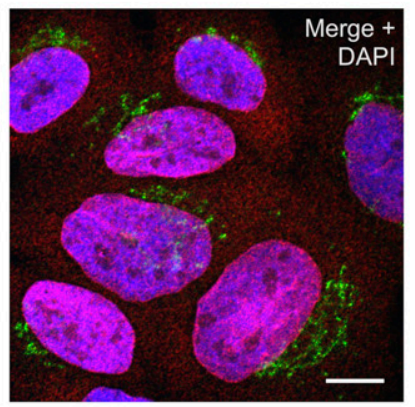

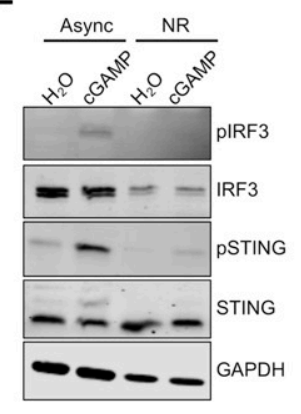
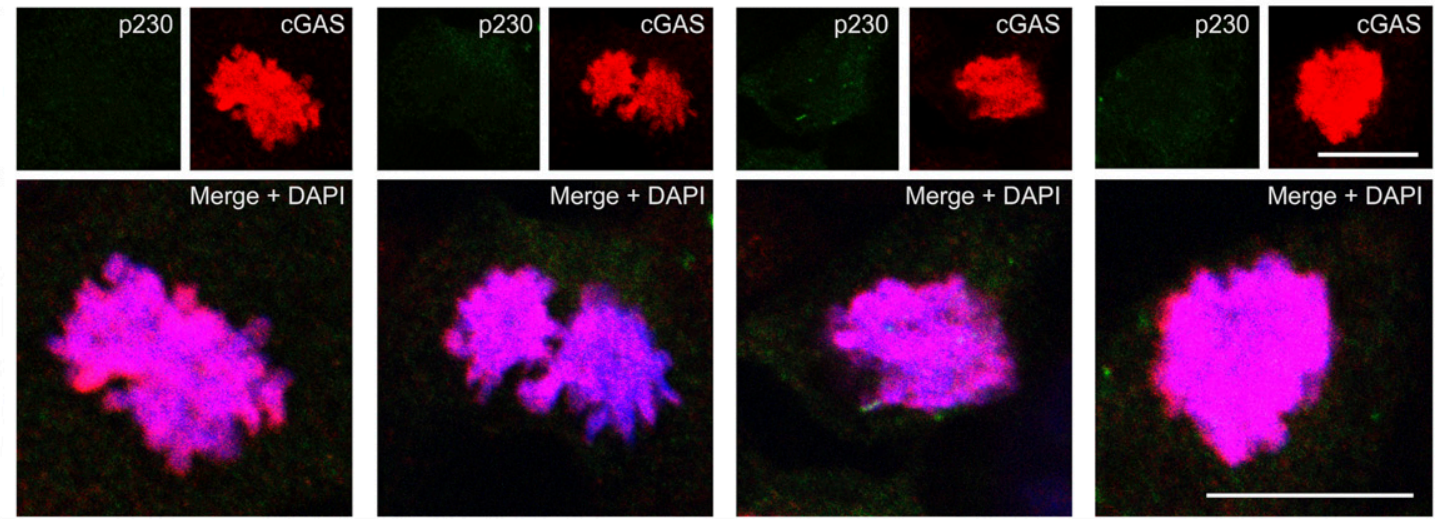

Figure 6. cGAS and STING are nonresponsive during mitosis.

(A) Mitotic phospho-IRF3 and phospho-STING responses to pGL3. Asynchronous and arrested cells were stimulated by transfection of 500 ng pGL3 or water for 90 min before Western blots. (B) Mitotic CGAMP responses to pGL3. Asynchronous and arrested cells were transfected with 500 ng pGL3. Non-internalized transfection complexes were removed by media change $2 \mathrm{~h}$ after the initial transfection. $5 \mathrm{~h}$ post-transfection, cGAMP levels were measured by ELISA. ${ }^{*} P<0.05, \mathrm{n}=2 \mathrm{biological}$ replicates, with $\mathrm{n}=2$ technical replicates each. (C, D) cGAS subcellular localization and Golgi morphology in asynchronous (C) and arrested (D) HaCaT cells. Scale bars = $10 \mu \mathrm{m}$. (E) Mitotic phospho-IRF3 and phospho-STING responses to exogenous cGAMP. Asynchronous and arrested cells were treated with 25 $\mu \mathrm{g} / \mathrm{ml} 2^{\prime}$ - 3 ' $\mathrm{CGAMP}$ for $2 \mathrm{~h}$ before Western blots. Source data are available for this figure.

$24 \mathrm{~h}$ post-siRnA transfection, as described above. At 90 min posttransfection, samples were collected for Western blotting as described above.

\section{Golgi disruption}

HaCaTs were plated at 60,000 cells per well on glass coverslips in 24-well plates. The following day, cells were treated with $5 \mu \mathrm{M}$ nocodazole (sc-3518; Santa Cruz), $10 \mu$ M golgicide A (sc-215103; Santa Cruz), or 150 nM brefeldin A (B6542; Sigma-Aldrich), or DMSO vehicle for $1 \mathrm{~h}$ before further experimental treatments, and drugs were left on for the duration of these experiments.

\section{Cell synchronization}

HaCaTs were plated at 7.5 million cells on a 10-cm dish in 10\% FBS/ DMEM and allowed to reach $100 \%$ confluence. The day after plating, the medium was changed to $1 \%$ FBS/DMEM and cells remained under contact inhibition at low-serum conditions for $48 \mathrm{~h}$ to synchronize at $\mathrm{G}_{0}$. Cells were then replated at 30,000 cells per well on 24-well plates with or without glass coverslips in 10\% FBS/DMEM and allowed to progress through the $S$ phase. After $24 \mathrm{~h}$, the cells were treated with $50 \mathrm{ng} / \mathrm{ml}$ nocodazole (sc-3518; Santa Cruz) for $12 \mathrm{~h}$ to synchronize at the prometaphase, at which point they were released with two PBS washes and incubated in 10\% FBS/DMEM. Cells were transfected with pGL3 as described above, and either harvested for Western blotting or prepared for IF or cell cycle analysis as described.

\section{Cell cycle analysis}

Cell cycle status was analyzed by PI incorporation and flow cytometry. HaCaTs synchronized in the manner described above. At various time points during the synchronization and release from the prometaphase, cells were collected by trypsinization and pelleted at $500 \mathrm{~g}$ for $10 \mathrm{~min}$ at $4^{\circ} \mathrm{C}$. The pellet was resuspended in ice-cold $70 \%$ ethanol to fix the cells and stored at $-20^{\circ} \mathrm{C}$ until ready for PI staining. Fixed cells were pelleted at $1,000 \mathrm{~g}$ for $15 \mathrm{~min}$ at $4^{\circ} \mathrm{C}$, resuspended in $\mathrm{PBS}, \mathrm{pH} 7.4$, containing 40 $\mu \mathrm{g} / \mathrm{ml} \mathrm{PI}$ and $500 \mu \mathrm{g} / \mathrm{ml}$ RNase A, and incubated at $37^{\circ} \mathrm{C}$ for $30 \mathrm{~min}$. Plstained cells were analyzed using the BD Biosciences FACSCanto-II flow cytometer and Diva 8.0 software.

\section{Immunofluorescent staining}

HaCaTs were plated at 60,000 cells per well on glass coverslips in 24-well plates. The following day, cells were treated and transfected as described above. For mitotic sync experiments: HaCaTs were synchronized 
to prometaphase as described above. For all experiments, after transfection, cells were fixed with $2 \%$ paraformaldehyde/PBS for 10 min at RT and permeabilized with $0.2 \%$ Triton X-100/PBS for 10 min at RT. Samples were blocked in $4 \% \mathrm{BSA} / 1 \%$ goat serum/PBS overnight at $4^{\circ} \mathrm{C}$. Rabbit polyclonal anti-TGN46 (T7576. 1:500; Sigma-Aldrich), mouse monoclonal anti-p230 (611280, 1:500; BD Biosciences), mouse monoclonal anti-IRF3 (ab50772, 1:100; Abcam), rabbit anti-cGAS (15102, 1:100; Cell Signaling), and rabbit monoclonal anti-STING (ab181125, 1:500; Abcam) were used as primary antibodies. Alexa Fluor-488, Alexa Fluor-555, and Alexa Fluor-647 labeled goat antimouse and goat antirabbit secondary antibodies (A11029, A21424, A21429, and A21236; Life Technologies) were used at 1:1,000. Samples were then stained with 4',6-diamidino-2-phenylindole (DAPI) (D9542-10MG; Sigma-Aldrich) at $1 \mu \mathrm{g} / \mathrm{ml}$ for $30 \mathrm{~s}$. Coverslips were mounted on glass slides with Prolong Antifade Diamond (P36970; Life Technologies) and analyzed by confocal microscopy.

\section{Confocal microscopy}

After the preparation of IF slides, confocal microscopy was performed using a Zeiss LSM880 system with 405, 488, and 543 nm lasers. Samples were examined using an oiled $63 \times$ objective, and Z-stacks with a $0.32 \mu \mathrm{m}$ depth per plane were taken of each image. Representative single-plane images and Z-stacks were processed with the Zen Blue software.

\section{Colocalization analysis}

Manders' overlap coefficients (102) for a STING:p230 and IRF3:DAPI channels within individual Z-stacks were determined using the JACoP plugin (103) on Image (104). Manual thresholds were set below saturation. Individual Manders overlap coefficient values and mean values from multiple Z-stacks (each containing multiple cells), across multiple fields of view, were plotted with GraphPad Prism software.

\section{cGAMP stimulation}

HaCaTs were plated at 60,000 asynchronous cells or 130,000 synchronous cells per well in 24-well plates. Cells were treated with 12.5 or $25 \mathrm{\mu g} / \mathrm{ml}$ 2'-3'CGAMP (tlrl-nacga23; Invivogen) for $2 \mathrm{~h}$ as indicated, then harvested for Western blotting as described above.

\section{SDS-PAGE and Western blotting}

Samples were resolved by SDS-PAGE and transferred onto a $0.45-$ $\mu \mathrm{m}$ nitrocellulose membrane. Rabbit monoclonal anti-GAPDH (2118, 1:5,000; Cell Signaling), mouse monoclonal anti-IRF3 (50772, 1:100; Abcam), rabbit monoclonal anti-TBK1 (3504, 1:1,000; Cell Signaling), and rabbit monoclonal anti-STING (13647, 1:1,000; Cell Signaling) blots were blocked in 5\% nonfat powdered milk dissolved in Trisbuffered saline containing $0.1 \%$ Tween (TBST). Rabbit monoclonal anti-phospho-IRF3 (Ser396 4947, 1:1,000; Cell Signaling), rabbit monoclonal anti-phospho-STING (Ser366 19781, 1:1,000; Cell Signaling), rabbit monoclonal anti-phospho-TBK1 (Ser172 5483, 1:1,000; Cell Signaling), and rabbit monoclonal anti-phospho-H3 (Ser10 3377, 1:10,000; Cell Signaling) blots were blocked in 100\% Odyssey Blocking Buffer (927-40000; LI-COR). Goat antirabbit DyLight 680
(3568; Pierce), goat antimouse DyLight 680 (35518; Pierce), goat antirabbit DyLight 800 (535571; Pierce), and goat antimouse DyLight 800 (35521; Pierce) were used as secondary antibodies at 1:10,000 in either $50 \%$ Odyssey Blocking Buffer/TBST or $5 \%$ milk/TBST. Blots were imaged with the Licor Odyssey Infrared Imaging System. Band intensities were quantified by densitometry using ImageJ v1.52a (104).

\section{CGAMP ELISA}

After Golgi vesiculation and mitotic sync experiments, cells were washed $1 \times$ with PBS and prepared for CGAMP quantification by the 2',3'-Cyclic GAMP Direct ELISA Kit (K067-H1; Arbor Assays), following the manufacturer's protocol. cGAMP concentrations were normalized by total protein concentration, as determined by BCA Assay (23225; Thermo Fisher Scientific).

\section{RT-qPCR experiments}

After Golgi disruption with GCA and transfection with pGL3, total RNA was prepared from HaCaTs using the QIAGEN RNeasy Mini Kit (74104; QIAGEN). RNA was isolated at 4 and $8 \mathrm{~h}$ post-pGL3 transfection. In the final step, RNA was eluted in $45 \mu \mathrm{l}$ RNase/DNase-free water. RNA samples were purified using the TURBO DNA-free Kit (AM1907; Life Technologies), and cDNA was prepared using the High Capacity cDNA Reverse Transcription Kit (4368814; Thermo Fisher Scientific). To prepare CDNA, $1 \mu \mathrm{g}$ of RNA was used per $40 \mu \mathrm{l}$ final reaction volume, yielding an estimated cDNA concentration of $25 \mathrm{ng} / \mu \mathrm{l}$. cDNA was diluted to $3.3 \mathrm{ng} / \mu \mathrm{l}$ with RNase/DNase-free water before use in qPCR. Reactions with specific ISG/IFN or TATA-binding protein (TBP) housekeeper primers were prepared using the PowerUp SYBR Green Master Mix Kit (A25742; Thermo Fisher Scientific) and loaded onto a 384-well plate. The reactions were run on a QuantStudio6 Flex Real-Time PCR System (Thermo Fisher Scientific). Delta-delta-cycle threshold $(\triangle \Delta \mathrm{Ct})$ was determined relative to vehicle treated samples. Viral RNA levels were normalized to TBP housekeeper and depicted as fold change over vehicle treated samples. Error bars indicate the SEM from $n=3$ technical replicates. Primer sequences are as follows: TBP-for; 5'-TAAACTTGACCTAAA GACCATTGCA-3', TBP-rev; 5'-CAGCAAACCGCTTGGGATTA-3', IFNB1-for; 5'CTTGGATTCCTACAAAGAAGCAGC-3', IFNB1-rev; 5' -TCCTCCTTCTGGAACTGC TGCA-3', viperin-for; 5'-CCAGTGCAACTACAAATGCGGC-3', viperin-rev, 5'-CGGTCTTGAAGAAATGGCTCTCC-3', IFI6-for; 5'-TGATGAGCTGGTCTG CGATCCT-3', IFI6-rev; 5'-GTAGCCCATCAGGGCACCAATA-3', HERC5-for; 5'-CAACTGGGAGAGCCTTGTGGTT-3', HERC5-rev; 5'-CTGGACCAGTTTG CTGAAAGTGG-3', IFIT2-for; 5'-GGAGCAGATTCTGAGGCTTTGC-3', IFIT2-rev; 5'-GGATGAGGCTTCCAGACTCCAA-3', IFIT3-for; 5' -CCTGGAATGCTTACGGCAAGCT-3', IFIT3-rev; 5'-GAGCATCTGAGAGTCTGCCCAA-3', CXCL10-for; 5'-GGTGAGAAGAGATGTCTGAATCC-3', CXCL10-rev; 5'-GTCCATCCTTGGAAGCACTGCA-3', CXCL11-for; 5'-AAGGACAACGATGCCTAAATCCC-3', CXCL11-rev; 5'-CAGATGCCCTTTTCCAGGACTTC-3'.

\section{Statistics}

Statistical analyses were performed using Prism 6 (GraphPad Software). Statistics for the pIRF3 blot densitometry from Golgi vesiculation experiments were determined by an unpaired $t$ test with the Holm-Sidak correction. Statistics for the cGAMP ELISAs and 
pIRF3 densitometry in Fig 5 were determined by ordinary one-way ANOVA with the Tukey correction for multiple comparisons. RTqPCR data were analyzed by two-way ANOVA with Tukey's multiple comparison. Colocalization statistics were calculated using a twosample unpaired t test as recommended for colocalization analysis (105). Error bars on graphs represent standard error of mean. Number of biological and technical replicates is noted in figure legends.

\section{Supplementary Information}

Supplementary Information is available at https://doi.org/10.26508/lsa. 201900636.

\section{Acknowledgements}

We are grateful to Jim DeCaprio for advice on cell synchronization, Koenraad Van Doorslaer, Robert Jackson, and David Williams for their assistance with RT-qPCR, helpful discussion, and critical reading of this manuscript and Joshua Uhlorn for discussion and advice on statistics. We thank Anne Cress for the HaCaT cell line. We thank the University of Arizona (UA) BIO5 Media Facility, Patty Jansma of the UA Imaging Core-Marley, and John Fitch of the UA Cancer Center/Arizona Research Laboratories Cytometry Core Facility. This work was supported by grant R01Al108751 from the National Institute for Allergy and Infectious Diseases, grant R01GM136853 from the National Institute for General Medical Sciences, and grant from the Sloan Scholars Mentoring Network of the Social Science Research Council with funds provided by the Alfred P Sloan Foundation. BL Uhlorn is a graduate student supported by the National Science Foundation Graduate Research Fellowship Grant DGE-1143953.

\section{Author Contributions}

BL Uhlorn: conceptualization, formal analysis, investigation, visualization, methodology, and writing-original draft, review, and editing.

ER Gamez: investigation and writing-original draft.

S Li: formal analysis, investigation, and visualization.

SK Campos: conceptualization, formal analysis, supervision, funding acquisition, visualization, methodology, project administration, and writing-original draft, review, and editing.

\section{Conflict of Interest Statement}

The authors declare that they have no conflict of interest.

\section{References}

1. Medzhitov R (2007) Recognition of microorganisms and activation of the immune response. Nature 449: 819-826. doi:10.1038/nature06246

2. Takeuchi O, Akira S (2010) Pattern recognition receptors and inflammation. Cell 140: 805-820. doi:10.1016/j.cell.2010.01.022

3. Stetson D, Medzhitov R (2006) Type I interferons in host defense. Immunity 25: 373-381. doi:10.1016/j.immuni.2006.08.007

4. Wu J, Chen Z (2014) Innate immune sensing and signaling of cytosolic nucleic acids. Annu Rev Immunol 32: 461-488. doi:10.1146/annurevimmunol-032713-120156
5. Li T, Chen Z (2018) The cGAS-cGAMP-STING pathway connects DNA damage to inflammation, senescence, and cancer. J Exp Med 215: 1287-1299. doi:10.1084/jem.20180139

6. Chen Q, Sun L, Chen Z (2016) Regulation and function of the CGAS-STING pathway of cytosolic DNA sensing. Nat Immunol 17: 1142-1149. doi:10.1038/ni.3558

7. Tao J, Zhou X, Jiang Z (2016) cGAS-cGAMP-STING: The three musketeers of cytosolic DNA sensing and signaling. IUBMB Life 68: 858-870. doi:10.1002/iub.1566

8. Stetson D, Medzhitov R (2006) Recognition of cytosolic DNA activates an IRF3-dependent innate immune response. Immunity 24: 93-103. doi:10.1016/j.immuni.2005.12.003

9. Sun L, Wu J, Du F, Chen X, Chen Z (2013) Cyclic GMP-AMP synthase is a cytosolic DNA sensor that activates the type I interferon pathway. Science 339: 786-791. doi:10.1126/science.1232458

10. Ishikawa $\mathrm{H}$, Barber $\mathrm{G}$ (2008) STING is an endoplasmic reticulum adaptor that facilitates innate immune signalling. Nature 455: 674-678. doi:10.1038/nature07317

11. Ishikawa H, Ma Z, Barber G (2009) STING regulates intracellular DNAmediated, type I interferon-dependent innate immunity. Nature 461: 788-792. doi:10.1038/nature08476

12. Yin Q, Tian Y, Kabaleeswaran V, Jiang X, Tu D, Eck M, Chen Z, Wu H (2012) Cyclic di-GMP sensing via the innate immune signaling protein STING. Mol Cell 46: 735-745. doi:10.1016/j.molcel.2012.05.029

13. Gao P, Ascano M, Zillinger T, Wang W, Dai P, Serganov A, Gaffney B, Shuman S, Jones R, Deng L, et al (2013) Structure-function analysis of STING activation by $\mathrm{c}\left[\mathrm{G}\left(2^{\prime}, 5^{\prime}\right) \mathrm{pA}\left(3^{\prime}, 5^{\prime}\right) \mathrm{p}\right]$ and targeting by antiviral DMXAA. Cell 154: 748-762. doi:10.1016/j.cell.2013.07.023

14. Ogawa E, Mukai K, Saito K, Arai H, Taguchi T (2018) The binding of TBK1 to STING requires exocytic membrane traffic from the ER. Biochem Biophys Res Commun 503: 138-145. doi:10.1016/j.bbrc.2018.05.199

15. Tanaka Y, Chen Z (2012) STING specifies IRF3 phosphorylation by TBK1 in the cytosolic DNA signaling pathway. Sci Signal 5: ra20. doi:10.1126/ scisignal.2002521

16. Abe T, Barber G (2014) Cytosolic-DNA-mediated, STING-dependent proinflammatory gene induction necessitates canonical NF-kappaB activation through TBK1. J Virol 88: 5328-5341. doi:10.1128/jvi.00037-14

17. Honda K, Taniguchi T (2006) IRFs: Master regulators of signalling by Toll-like receptors and cytosolic pattern-recognition receptors. Nat Rev Immunol 6: 644-658. doi:10.1038/nri1900

18. Luo W, Li S, Li C, Lian H, Yang Q, Zhong B, Shu H (2016) iRhom2 is essential for innate immunity to DNA viruses by mediating trafficking and stability of the adaptor STING. Nat Immunol 17: 1057-1066. doi:10.1038/ni.3510

19. Sun M, Zhang J, Jiang L, Pan Y, Tan J, Yu F, Guo L, Yin L, Shen C, Shu H, et al (2018) TMED2 potentiates cellular IFN responses to DNA viruses by reinforcing MITA dimerization and facilitating its trafficking. Cell Rep 25: 3086-3098.e3. doi:10.1016/j.celrep.2018.11.048

20. Srikanth S, Woo J, Wu B, El-Sherbiny Y, Leung J, Chupradit K, Rice L, Seo G, Calmettes G, Ramakrishna C, et al (2019) The Ca(2+) sensor STIM1 regulates the type I interferon response by retaining the signaling adaptor STING at the endoplasmic reticulum. Nat Immunol 20: 152-162. doi:10.1038/s41590-018-0287-8

21. Li Y, James S, Wyllie D, Wynne C, Czibula A, Bukhari A, Pye K, Bte Mustafah S, Fajka-Boja R, Szabo E, et al (2019) TMEM203 is a binding partner and regulator of STING-mediated inflammatory signaling in macrophages. Proc Natl Acad Sci U S A 116: 16479-16488. doi:10.1073/pnas.1901090116

22. Saitoh T, Fujita N, Hayashi T, Takahara K, Satoh T, Lee H, Matsunaga K, Kageyama S, Omori H, Noda T, et al (2009) Atg9a controls dsDNA-driven dynamic translocation of STING and the innate immune response. Proc Natl Acad Sci U S A 106: 20842-20846. doi:10.1073/pnas.0911267106 
23. Mukai K, Konno H, Akiba T, Uemura T, Waguri S, Kobayashi T, Barber G, Arai $\mathrm{H}$, Taguchi T (2016) Activation of STING requires palmitoylation at the Golgi. Nat Commun 7: 11932. doi:10.1038/ncomms11932

24. Tsuchida T, Zou J, Saitoh T, Kumar H, Abe T, Matsuura Y, Kawai T, Akira S (2010) The ubiquitin ligase TRIM56 regulates innate immune responses to intracellular double-stranded DNA. Immunity 33: 765-776. doi:10.1016/j.immuni.2010.10.013

25. Zhang J, Hu M, Wang Y, Shu H (2012) TRIM32 protein modulates type I interferon induction and cellular antiviral response by targeting MITA/ STING protein for K63-linked ubiquitination. J Biol Chem 287: 28646-28655. doi:10.1074/jbc.m112.362608

26. Shang G, Zhang C, Chen Z, Bai X, Zhang X (2019) Cryo-EM structures of STING reveal its mechanism of activation by cyclic GMP-AMP. Nature 567: 389-393. doi:10.1038/s41586-019-0998-5

27. Ergun S, Fernandez D, Weiss T, Li L (2019) STING polymer structure reveals mechanisms for activation, hyperactivation, and inhibition. Cell 178: 290-301.e10. doi:10.1016/j.cell.2019.05.036

28. Zhang C, Shang G, Gui X, Zhang X, Bai X, Chen Z (2019) Structural basis of STING binding with and phosphorylation by TBK1. Nature 567: 394-398. doi:10.1038/s41586-019-1000-2

29. Chen W, Li S, Yu H, Liu X, Huang L, Wang Q, Liu H, Cui Y, Tang Y, Zhang P, et al (2016) ER adaptor SCAP translocates and recruits IRF3 to perinuclear microsome induced by cytosolic microbial DNAs. PLOS Pathog 12: e1005462. doi:10.1371/journal.ppat.1005462

30. Ablasser A, Chen Z (2019) cGAS in action: Expanding roles in immunity and inflammation. Science 363: eaat8657. doi:10.1126/science.aat8657

31. Bakhoum S, Ngo B, Laughney A, Cavallo J, Murphy C, Ly P, Shah P, Sriram R, Watkins T, Taunk N, et al (2018) Chromosomal instability drives metastasis through a cytosolic DNA response. Nature 553: 467-472. doi:10.1038/nature25432

32. Gluck S, Guey B, Gulen M, Wolter K, Kang T, Schmacke N, Bridgeman A, Rehwinkel J, Zender L, Ablasser A (2017) Innate immune sensing of cytosolic chromatin fragments through cGAS promotes senescence. Nat Cell Biol 19: 1061-1070. doi:10.1038/ncb3586

33. Harding S, Benci J, Irianto J, Discher D, Minn A, Greenberg R (2017) Mitotic progression following DNA damage enables pattern recognition within micronuclei. Nature 548: 466-470. doi:10.1038/nature23470

34. Mackenzie K, Carroll P, Martin C, Murina O, Fluteau A, Simpson D, Olova $\mathrm{N}$, Sutcliffe H, Rainger J, Leitch A, et al (2017) CGAS surveillance of micronuclei links genome instability to innate immunity. Nature 548 461-465. doi:10.1038/nature23449

35. Yang H, Wang H, Ren J, Chen Q, Chen Z (2017) cGAS is essential for cellular senescence. Proc Natl Acad Sci U S A 114: E4612-E4620. doi:10.1073/pnas.1705499114

36. Dou Z, Ghosh K, Vizioli M, Zhu J, Sen P, Wangensteen K, Simithy J, Lan Y, Lin Y, Zhou Z, et al (2017) Cytoplasmic chromatin triggers inflammation in senescence and cancer. Nature 550: 402-406. doi:10.1038/ nature24050

37. Motwani M, Pesiridis S, Fitzgerald K (2019) DNA sensing by the cGASSTING pathway in health and disease. Nat Rev Genet 20: 657-674 doi:10.1038/s41576-019-0151-1

38. Konno H, Chinn I, Hong D, Orange J, Lupski J, Mendoza A, Pedroza L, Barber G (2018) Pro-inflammation associated with a gain-of-function mutation (R284S) in the innate immune sensor STING. Cell Rep 23: 1112-1123. doi:10.1016/j.celrep.2018.03.115

39. Liu Y, Jesus A, Marrero B, Yang D, Ramsey S, Sanchez G, Tenbrock K, Wittkowski H, Jones O, Kuehn H, et al (2014) Activated STING in a vascular and pulmonary syndrome. N Engl J Med 371: 507-518. doi:10.1056/nejmoa1312625

40. Picard C, Thouvenin G, Kannengiesser C, Dubus J, Jeremiah N, RieuxLaucat F, Crestani B, Belot A, Thivolet-Bejui F, Secq V, et al (2016) Severe pulmonary fibrosis as the first manifestation of interferonopathy (TMEM173 mutation). Chest 150: e65-e71. doi:10.1016/j.chest.2016.02.682

41. Saldanha R, Balka K, Davidson S, Wainstein B, Wong M, Macintosh R, Loo C, Weber M, Kamath V, Moghaddas F, et al (2018) A mutation outside the dimerization domain causing atypical STING-associated vasculopathy with onset in infancy. Front Immunol 9: 1535. doi:10.3389/ fimmu.2018.01535

42. Davidson S, Steiner A, Harapas C, Masters S (2018) An update on autoinflammatory diseases: Interferonopathies. Curr Rheumatol Rep 20: 38. doi:10.1007/s11926-018-0748-y

43. Stetson D, Ko J, Heidmann T, Medzhitov R (2008) Trex1 prevents cellintrinsic initiation of autoimmunity. Cell 134: 587-598. doi:10.1016/ j.cell.2008.06.032

44. Gray E, Treuting P, Woodward J, Stetson D (2015) Cutting edge: CGAS is required for lethal autoimmune disease in the Trex1-deficient mouse model of aicardi-goutieres syndrome. I Immunol 195: 1939-1943. doi:10.4049/jimmunol.1500969

45. Yoshida H, Okabe Y, Kawane K, Fukuyama H, Nagata S (2005) Lethal anemia caused by interferon-beta produced in mouse embryos carrying undigested DNA. Nat Immunol 6: 49-56. doi:10.1038/ni1146

46. Sun C, Luecke S, Bodda C, Jonsson K, Cai Y, Zhang B, Jensen S, Nordentoft I, Jensen J, Jakobsen M, et al (2019) Cellular requirements for sensing and elimination of incoming HSV-1 DNA and capsids. I Interferon Cytokine Res 39: 191-204. doi:10.1089/jir.2018.0141

47. Hare D, Collins S, Mukherjee S, Loo Y, Gale M Jr., Janssen L, Mossman K (2015) Membrane perturbation-associated Ca2+ signaling and incoming genome sensing are required for the host response to lowlevel enveloped virus particle entry. J Virol 90: 3018-3027. doi:10.1128/ jvi.02642-15

48. Lam E, Stein S, Falck-Pedersen E (2014) Adenovirus detection by the CGAS/STING/TBK1 DNA sensing cascade. J Virol 88: 974-981. doi:10.1128/ jvi.02702-13

49. Wang F, Alain T, Szretter K, Stephenson K, Pol J, Atherton M, Hoang H, Fonseca B, Zakaria C, Chen L, et al (2016) S6K-STING interaction regulates cytosolic DNA-mediated activation of the transcription factor IRF3. Nat Immunol 17: 514-522. doi:10.1038/ni.3433

50. Watkinson R, McEwan W, Tam J, Vaysburd M, James L (2015) TRIM21 promotes CGAS and RIG-I sensing of viral genomes during infection by antibody-opsonized virus. PLoS Pathog 11: e1005253. doi:10.1371/ journal.ppat.1005253

51. Dai P, Wang W, Cao H, Avogadri F, Dai L, Drexler I, Joyce J, Li X, Chen Z, Merghoub T, et al (2014) Modified vaccinia virus Ankara triggers type I IFN production in murine conventional dendritic cells via a cGAS/ STING-mediated cytosolic DNA-sensing pathway. PLoS Pathog 10: e1003989. doi:10.1371/journal.ppat.1003989

52. Garcia-Belmonte R, Perez-Nunez D, Pittau M, Richt J, Revilla Y (2019) African swine fever virus Armenia/ 07 virulent strain controls interferon beta production through the CGAS-STING pathway. J Virol 93: e02298-18. doi:10.1128/jvi.02298-18

53. Zierhut C, Yamaguchi N, Paredes M, Luo J, Carroll T, Funabiki H (2019) The cytoplasmic DNA sensor cGAS promotes mitotic cell death. Cell 178: 302-315.e23. doi:10.1016/j.cell.2019.05.035

54. Volkman H, Cambier S, Gray E, Stetson D (2019) Tight nuclear tethering of CGAS is essential for preventing autoreactivity. Elife 8: e47491. doi:10.7554/elife. 47491

55. Sutterlin C, Hsu P, Mallabiabarrena A, Malhotra V (2002) Fragmentation and dispersal of the pericentriolar Golgi complex is required for entry into mitosis in mammalian cells. Cell 109: 359-369. doi:10.1016/s00928674(02)00720-1

56. Tang D, Wang Y (2013) Cell cycle regulation of Golgi membrane dynamics. Trends Cell Biol 23: 296-304. doi:10.1016/j.tcb.2013.01.008 
57. Boukamp P, Petrussevska R, Breitkreutz D, Hornung J, Markham A, Fusenig N (1988) Normal keratinization in a spontaneously immortalized aneuploid human keratinocyte cell line. J Cell Biol 106: 761-771. doi:10.1083/jcb.106.3.761

58. Bernard E, Hamel R, Neyret A, Ekchariyawat P, Moles J, Simmons G, Chazal N, Despres P, Misse D, Briant L (2015) Human keratinocytes restrict chikungunya virus replication at a post-fusion step. Virology 476: 1-10. doi:10.1016/j.virol.2014.11.013

59. Griffin L, Cicchini L, XU T, Pyeon D (2014) Human keratinocyte cultures in the investigation of early steps of human papillomavirus infection. Methods Mol Biol 1195: 219-238. doi:10.1007/7651_2013_49

60. Kim J, Seong R, Son S, Shin O (2019) Insights into ZIKV-mediated innate immune responses in human dermal fibroblasts and epidermal keratinocytes. J Invest Dermatol 139: 391-399. doi:10.1016/ j.jid.2018.07.038

61. Lim P, Behr M, Chadwick C, Shi P, Bernard K (2011) Keratinocytes are cell targets of West Nile virus in vivo. J Virol 85: 5197-5201. doi:10.1128/ jvi.02692-10

62. Lopez-Gonzalez M, Meza-Sanchez D, Garcia-Cordero J, Bustos-Arriaga J, Velez-Del Valle C, Marsch-Moreno M, Castro-Jimenez T, Flores-Romo L, Santos-Argumedo L, Gutierrez-Castaneda B, et al (2018) Human keratinocyte cultures ( $\mathrm{HaCaT}$ ) can be infected by DENV, triggering innate immune responses that include IFNlambda and LL37. Immunobiology 223: 608-617. doi:10.1016/j.imbio.2018.07.006

63. Puiprom O, Morales Vargas R, Potiwat R, Chaichana P, Ikuta K, Ramasoota P, Okabayashi T (2013) Characterization of chikungunya virus infection of a human keratinocyte cell line: Role of mosquito salivary gland protein in suppressing the host immune response. Infect Genet Evol 17: 210-215. doi:10.1016/j.meegid.2013.04.005

64. Rahn E, Petermann P, Hsu M, Rixon F, Knebel-Morsdorf D (2011) Entry pathways of herpes simplex virus type 1 into human keratinocytes are dynamin- and cholesterol-dependent. PLoS One 6: e25464. doi:10.1371/ journal.pone.0025464

65. Kisich K, Howell M, Boguniewicz M, Heizer H, Watson N, Leung D (2007) The constitutive capacity of human keratinocytes to kill Staphylococcus aureus is dependent on beta-defensin 3. I Invest Dermatol 127: 2368-2380. doi:10.1038/sj.jid.5700861

66. Petrucelli M, Peronni K, Sanches P, Komoto T, Matsuda J, Silva Junior W, Beleboni R, Martinez-Rossi N, Marins M, Fachin A (2018) Dual RNA-seq analysis of trichophyton rubrum and HaCat keratinocyte Co-culture highlights important genes for fungal-host interaction. Genes (Basel) 9: 362. doi:10.3390/genes 9070362

67. Almine J, O'Hare C, Dunphy G, Haga I, Naik R, Atrih A, Connolly D, Taylor J, Kelsall I, Bowie A, et al (2017) IFI16 and CGAS cooperate in the activation of STING during DNA sensing in human keratinocytes. Nat Commun 8: 14392. doi:10.1038/ncomms14392

68. Dunphy G, Flannery S, Almine J, Connolly D, Paulus C, Jonsson K, Jakobsen M, Nevels M, Bowie A, Unterholzner L (2018) Non-canonical activation of the DNA sensing adaptor STING by ATM and IFI16 mediates NF-kappaB signaling after nuclear DNA damage. Mol Cell 71: 745-760.e5. doi:10.1016/j.molcel.2018.07.034

69. Kim J, Park S, Seo S, Lee C, Shin O (2017) STING is involved in antiviral immune response against VZV infection via the induction of type I and III IFN pathways. J Invest Dermatol 137: 2101-2109. doi:10.1016/ j.jid.2017.03.041

70. Olagnier D, Brandtoft A, Gunderstofte C, Villadsen N, Krapp C, Thielke A, Laustsen A, Peri S, Hansen A, Bonefeld L, et al (2018) Nrf2 negatively regulates STING indicating a link between antiviral sensing and metabolic reprogramming. Nat Commun 9: 3506. doi:10.1038/s41467018-05861-7

71. Skouboe M, Knudsen A, Reinert L, Boularan C, Lioux T, Perouzel E, Thomsen M, Paludan S (2018) STING agonists enable antiviral cross-talk between human cells and confer protection against genital herpes in mice. PLoS Pathog 14: e1006976. doi:10.1371/journal.ppat.1006976

72. Cole N, Sciaky N, Marotta A, Song J, Lippincott-Schwartz J (1996) Golgi dispersal during microtubule disruption: Regeneration of Golgi stacks at peripheral endoplasmic reticulum exit sites. Mol Biol Cell 7: 631-650. doi:10.1091/mbc.7.4.631

73. Helms J, Rothman J (1992) Inhibition by brefeldin A of a Golgi membrane enzyme that catalyses exchange of guanine nucleotide bound to ARF. Nature 360: 352-354. doi:10.1038/360352a0

74. Saenz J, Sun W, Chang J, Li J, Bursulaya B, Gray N, Haslam D (2009) Golgicide A reveals essential roles for GBF1 in Golgi assembly and function. Nat Chem Biol 5: 157-165. doi:10.1038/nchembio.144

75. Gui X, Yang H, Li T, Tan X, Shi P, Li M, Du F, Chen Z (2019) Autophagy induction via STING trafficking is a primordial function of the CGAS pathway. Nature 567: 262-266. doi:10.1038/s41586-019-1006-9

76. Kawai T, Takahashi K, Sato S, Coban C, Kumar H, Kato H, Ishii K, Takeuchi O, Akira S (2005) IPS-1, an adaptor triggering RIG-I- and Mda5-mediated type I interferon induction. Nat Immunol 6: 981-988. doi:10.1038/ni1243

77. Yoneyama M, Kikuchi M, Natsukawa T, Shinobu N, Imaizumi T, Miyagishi M, Taira K, Akira S, Fujita T (2004) The RNA helicase RIG-I has an essential function in double-stranded RNA-induced innate antiviral responses. Nat Immunol 5: 730-737. doi:10.1038/ni1087

78. Farmaki T, Ponnambalam S, Prescott A, Clausen H, Tang B, Hong W, Lucocq J (1999) Forward and retrograde trafficking in mitotic animal cells. ER-Golgi transport arrest restricts protein export from the ER into COPII-coated structures. J Cell Sci 112: 589-600.

79. Kreiner T, Moore H (1990) Membrane traffic between secretory compartments is differentially affected during mitosis. Cell Regul 1: 415-424. doi:10.1091/mbc.1.5.415

80. Prescott A, Farmaki T, Thomson C, James J, Paccaud J, Tang B, Hong W, Quinn M, Ponnambalam S, Lucocq I (2001) Evidence for prebudding arrest of ER export in animal cell mitosis and its role in generating Golgi partitioning intermediates. Traffic 2: 321-335. doi:10.1034/j.16000854.2001.002005321.x

81. Warren G, Featherstone C, Griffiths G, Burke B (1983) Newly synthesized $G$ protein of vesicular stomatitis virus is not transported to the cell surface during mitosis. J Cell Biol 97: 1623-1628. doi:10.1083/jcb.97.5.1623

82. Hughes $H$, Stephens D (2010) Sec16A defines the site for vesicle budding from the endoplasmic reticulum on exit from mitosis. I Cell Sci 123: 4032-4038. doi:10.1242/jcs.076000

83. Ward T, Polishchuk R, Caplan S, Hirschberg K, Lippincott-Schwartz J (2001) Maintenance of Golgi structure and function depends on the integrity of ER export. J Cell Biol 155: 557-570. doi:10.1083/jcb.200107045

84. Luteijn R, Zaver S, Gowen B, Wyman S, Garelis N, Onia L, McWhirter S, Katibah G, Corn J, Woodward J, et al (2019) SLC19A1 transports immunoreactive cyclic dinucleotides. Nature 573: 434-438. doi:10.1038/ s41586-019-1553-0

85. Ritchie C, Cordova A, Hess G, Bassik M, Li L (2019) SLC19A1 is an importer of the immunotransmitter CGAMP. Mol Cell 75: 372-381.e5. doi:10.1016/ j.molcel.2019.05.006

86. Zhou C, Chen X, Planells-Cases R, Chu J, Wang L, Cao L, Li Z, LopezCayuqueo K, Xie Y, Ye S, et al (2020) Transfer of cGAMP into bystander cells via LRRC8 volume-regulated anion channels augments STINGmediated interferon responses and anti-viral immunity. Immunity 52: 767-781.e6. doi:10.1016/j.immuni.2020.03.016

87. Ablasser A, Schmid-Burgk J, Hemmerling I, Horvath G, Schmidt T, Latz E, Hornung V (2013) Cell intrinsic immunity spreads to bystander cells via the intercellular transfer of cGAMP. Nature 503: 530-534. doi:10.1038/ nature12640

88. Fykerud T, Knudsen L, Totland M, Sorensen V, Dahal-Koirala S, Lothe R, Brech A, Leithe E (2016) Mitotic cells form actin-based bridges with 
adjacent cells to provide intercellular communication during rounding. Cell Cycle 15: 2943-2957. doi:10.1080/15384101.2016.1231280

89. Odle R, Walker S, Oxley D, Kidger A, Balmanno K, Gilley R, Okkenhaug H, Florey O, Ktistakis N, Cook S (2019) An mTORC1-to-CDK1 switch maintains autophagy suppression during mitosis. Mol Cell 77: 228-240. doi:10.1016/j.molcel.2019.10.016.

90. Willson J (2019) Mitosis flips the switch on autophagy control. Nat Rev Mol Cell Biol 21: 4-5. doi:10.1038/s41580-019-0196-1

91. Eskelinen E, Prescott A, Cooper J, Brachmann S, Wang L, Tang X, Backer J, Lucocq J (2002) Inhibition of autophagy in mitotic animal cells. Traffic 3: 878-893. doi:10.1034/j.1600-0854.2002.31204.x

92. Mathiassen S, De Zio D, Cecconi F (2017) Autophagy and the cell cycle: A complex landscape. Front Oncol 7: 51. doi:10.3389/fonc.2017.00051

93. Zhong L, Hu M, Bian L, Liu Y, Chen Q, Shu H (2020) Phosphorylation of cGAS by CDK1 impairs self-DNA sensing in mitosis. Cell Discov 6: 26. doi:10.1038/s41421-020-0162-2

94. Cervigni R, Bonavita R, Barretta M, Spano D, Ayala I, Nakamura N, Corda D, Colanzi A (2015) JNK2 controls fragmentation of the Golgi complex and the G2/M transition through phosphorylation of GRASP65. J Cell Sci 128: 2249-2260. doi:10.1242/jcs.164871

95. Colanzi A, Hidalgo Carcedo C, Persico A, Cericola C, Turacchio G, Bonazzi M, Luini A, Corda D (2007) The Golgi mitotic checkpoint is controlled by BARS-dependent fission of the Golgi ribbon into separate stacks in G2. EMBO J 26: 2465-2476. doi:10.1038/sj.emboj.7601686

96. Corda D, Barretta M, Cervigni R, Colanzi A (2012) Golgi complex fragmentation in G2/M transition: An organelle-based cell-cycle checkpoint. IUBMB Life 64: 661-670. doi:10.1002/iub.1054

97. Canton J, Kima P (2012) Interactions of pathogen-containing compartments with the secretory pathway. Cell Microbiol 14: 1676-1686. doi:10.1111/cmi.12000
98. Machamer C (2015) The Golgi complex in stress and death. Front Neurosci 9: 421. doi:10.3389/fnins.2015.00421

99. Mousnier A, Swieboda D, Pinto A, Guedan A, Rogers A, Walton R, Johnston S, Solari R (2014) Human rhinovirus 16 causes Golgi apparatus fragmentation without blocking protein secretion. J Virol 88: 11671-11685. doi:10.1128/jvi.01170-14

100. Heuer D, Rejman Lipinski A, Machuy N, Karlas A, Wehrens A, Siedler F, Brinkmann V, Meyer T (2009) Chlamydia causes fragmentation of the Golgi compartment to ensure reproduction. Nature 457: 731-735. doi:10.1038/nature07578

101. Pierini R, Cottam E, Roberts R, Wileman T (2009) Modulation of membrane traffic between endoplasmic reticulum, ERGIC and Golgi to generate compartments for the replication of bacteria and viruses. Semin Cell Dev Biol 20: 828-833. doi:10.1016/j.semcdb.2009.03.015

102. Manders E, Verbeek F, Aten J (1993) Measurement of co-localization of objects in dual-colour confocal images. J Microsc 169: 375-382. doi:10.1111/j.1365-2818.1993.tb03313.x

103. Bolte S, Cordelieres F (2006) A guided tour into subcellular colocalization analysis in light microscopy. J Microsc 224: 213-232. doi:10.1111/j.1365-2818.2006.01706.x

104. Schneider C, Rasband W, Eliceiri K (2012) NIH image to Image): 25 years of image analysis. Nat Methods 9: 671-675. doi:10.1038/nmeth.2089

105. McDonald J, Dunn K (2013) Statistical tests for measures of colocalization in biological microscopy. J Microsc 252: 295-302. doi:10.1111/jmi.12093

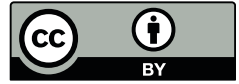

License: This article is available under a Creative Commons License (Attribution 4.0 International, as described at https://creativecommons.org/ licenses/by/4.0/). 